\title{
Thoracic endovascular aortic repair for chronic distal aortic dissection: The jury is still out
}

\author{
Bradley G. Leshnower, MD, and Vinod H. Thourani, MD
}

See related article on pages S163-7.

It is no surprise that after the successful application of endovascular therapy to treat atherosclerotic descending thoracic aortic aneurysms, thoracic endovascular aortic repair (TEVAR) is now being used for distal aortic dissection. TEVAR has revolutionized the treatment of patients with acute DeBakey III aortic dissection complicated by malperfusion or rupture and is universally acknowledged as the standard of care. ${ }^{1}$ However, the role of TEVAR in the treatment of chronic distal aortic dissection has yet to be elucidated.

The article by Dr Roselli ${ }^{2}$ eloquently outlines the pertinent issues currently surrounding open versus endovascular therapy for the treatment of chronic, complicated (ie, aneurysmal degeneration) distal aortic dissection. Open replacement of dissected, aneurysmal segments of the descending thoracic and abdominal aorta remains the gold standard and can be accomplished with mortality ranging from $2 \%$ to $8 \%$ in high-volume centers. ${ }^{3-5}$ These procedures are durable with 5-year survival of $70 \%$ to $79 \%$ and 5 -year freedom from reintervention rates of $85 \%$ to $92 \%$. However, these procedures are highly morbid and carry significant risks of adverse renal, respiratory, and neurologic events.

The minimally invasive TEVAR procedure is typically performed via a transfemoral approach that can be accomplished via a small groin incision or totally percutaneous access. The technical goal of TEVAR for chronic aortic dissection is to cover the primary intimal tear and all distal aortic fenestrations down to the celiac axis. The success of the procedure is based on the long-term capacity of the endograft to promote (1) true lumen expansion, (2) false lumen thrombosis and shrinkage, and (3) stabilization or a reduction in total aortic diameter. These changes are broadly categorized as "reverse aortic remodeling." TEVAR has been demonstrated to be a safe procedure for chronic complicated distal aortic dissection with an operative mortality of

From the Division of Cardiothoracic Surgery, Joseph B. Whitehead Department of Surgery, Emory University School of Medicine, Atlanta, Ga.

Disclosures: Authors have nothing to disclose with regard to commercial support. Received for publication Dec 2, 2014; accepted for publication Dec 3, 2014.

Address for reprints: Vinod H. Thourani, MD, Cardiac Surgery, Emory University Hospital Midtown, 550 Peachtree St, 6th Floor Medical Office Tower, Atlanta, GA 30308 (E-mail: vthoura@emory.edu).

J Thorac Cardiovasc Surg 2015;149:S168-9

$0022-5223 / \$ 36.00$

Copyright (c) 2015 by The American Association for Thoracic Surgery

http://dx.doi.org/10.1016/j.jtcvs.2014.12.004 less than 5\%. TEVAR also has been shown to significantly reduce the renal and neurologic complications associated with open descending/thoracoabdominal aortic replacement and eliminate the pulmonary complications by avoiding a thoracotomy. As with all endografting procedures, the trade-off for the reduction in perioperative morbidity and mortality is a higher reintervention rate compared with open descending aortic replacement. ${ }^{6-9}$

If endograft coverage of all intimal tears is feasible, as in DeBakey IIIa dissections, TEVAR is highly effective in remodeling the aorta and reducing total aortic diameter. However, the majority of chronic distal aortic dissections extend through the visceral aortic segment to the aortic bifurcation (residual DeBakey I or DeBakey IIIb). As Dr Roselli ${ }^{2}$ astutely emphasizes, these are the challenging patients in whom the efficacy of TEVAR is unclear. Reverse remodeling in these patients is inconsistent because of the presence of distal aortic fenestrations. These distal communications may result in persistent false lumen perfusion and the prevention of false lumen thrombosis and shrinkage. Indeed, the series by Kang and colleagues ${ }^{6}$ from Cleveland Clinic report a $78 \%$ success of total false lumen thrombosis in patients with IIIa dissections, but only a $13 \%$ total false lumen thrombosis with IIIb dissections. Similar results have been reported by several other high-volume aortic centers. ${ }^{7-9}$

A recent report from Hughes and colleagues ${ }^{9}$ demonstrated aneurysm sac regression greater than $1 \mathrm{~cm}$ in $89 \%$ of patients with chronic DeBakey IIIb dissections with aneurysmal degeneration limited to the descending thoracic aorta alone. These encouraging results highlight the concept that TEVAR will be highly efficacious in select cohorts of patients with chronic dissection who have favorable anatomy (ie, DeBakey IIIa, limited distal fenestrations). The current challenge is to identify which anatomic variants of distal aortic dissection possess "favorable anatomy." Unfortunately, the existing data are both limited and immature, and therefore unable to answer the question.

The "jury is still out" regarding the role of TEVAR for chronic aortic dissection extending distal to the celiac axis. We share Dr Roselli's ${ }^{2}$ opinion that TEVAR should be viewed as a complementary strategy, rather than a replacement for open surgery. TEVAR for chronic dissection is in its infancy, and outcomes will only improve as experience accumulates and "dissection-specific" devices become available. However, we believe that age, comorbidities, and anatomy will continue to serve as the primary determinants of whether patients receive open or endovascular 
therapy for the treatment of complicated chronic distal aortic dissection.

\section{References}

1. Szeto WY, McGarvey M, Pochettino A, Moser GW, Hoboken A, Cornelius K, et al. Results of a new surgical paradigm: endovascular repair for acute complicated type B aortic dissection. Ann Thorac Surg. 2008;86:87-93.

2. Roselli EE. Thoracic endovascular aortic repair versus open surgery for type-B chronic dissection. J Thorac Cardiovasc Surg. 2015;149:S163-7.

3. Coselli JS, Green SY, Zarda S, Nalty CC, Price MD, Hughes MS, et al. Outcomes of open distal aortic aneurysm repair in patients with chronic DeBakey type I dissection. J Thorac Cardiovasc Surg. 2014;148:2986-94.

4. Estrera AL, Sandhu H, Afifi RO, Azizzadeh A, Charlton-Ouw K, Miller CC, et al. Open repair of chronic complicated type B aortic dissection using the open distal technique. Ann Cardiothorac Surg. 2014;3:375-84.
5. Corvera JS, Fehrenbacher JW. Open repair of chronic aortic dissections us ing deep hypothermia and circulatory arrest. Ann Thorac Surg. 2012;94: 78-81.

6. Kang WC, Greenberg RK, Mastracci TM, Eagleton MJ, Hernandez AV, Pujara AC, et al. Endovascular repair of complicated chronic distal aortic dissections: Intermediate outcomes and complications. J Thorac Cardiovasc Surg. 2011; 142:1074-83.

7. Leshnower BG, Szeto WY, Pochettino A, Desai ND, Moeller PJ, Nathan DP, et al Thoracic endografting reduces morbidity and remodels the thoracic aorta in DeBakey III aneurysms. Ann Thorac Surg. 2013;95:914-21.

8. Rodriguez JA, Olsen DM, Lucas L, Wheatley G, Ramaiah V, Diethrich EB. Aortic remodeling after endografting of thoracoabdominal aortic dissection. J Vasc Surg. 2008:47:1188-94.

9. Hughes GC, Ganapathi AM, Keenan JE, Englum BR, Hanna JM, Schechter MA et al. Thoracic endovascular aortic repair for chronic DeBakey IIIb aortic dissection. Ann Thorac Surg. 2014;98:2092-8. 